\title{
Interpersonal Coordination Dynamics in Psychotherapy: A Systematic Review
}

\author{
Travis J. Wiltshire ${ }^{1,2}$ (D) Johanne Stege Philipsen ${ }^{2} \cdot$ Sarah Bro Trasmundi ${ }^{2} \cdot$ Thomas Wiben Jensen $^{2}$. \\ Sune Vork Steffensen ${ }^{2}$
}

Published online: 29 April 2020

(c) The Author(s) 2020

\begin{abstract}
Background The aim of this study was to gain a better understanding of interpersonal coordination (i.e., covariation over time) in different modalities (e.g., physiology, language) during psychotherapy and their importance for understanding the dynamics of psychotherapeutic interaction and efficacy.

Methods We conducted a systematic review of all studies examining some form of interpersonal coordination in a psychotherapeutic context.

Results We first summarize details of the included studies such as gender composition, therapy types, and methods used. The collation of these studies provided evidence that, during psychotherapeutic contexts, interpersonal coordination occurs in physiology, movements, interpersonal displays, and language/vocalizations. Further, it also showed that movement coordination was most frequently associated with psychotherapy outcomes, physiological coordination was most frequently associated with empathy, and coordination in a variety of modalities including language/vocalizations were most frequently associated with therapeutic alliance.

Conclusions We discuss these results, shortcomings with the current literature, and highlight three crucial questions for future research. Research on interpersonal coordination in psychotherapy has potential to advance the both the research and practice of psychotherapy.
\end{abstract}

Keywords Synchrony $\cdot$ Interaction $\cdot$ Psychotherapy $\cdot$ Outcome research $\cdot$ Alliance $\cdot$ Empathy

\section{Introduction}

Psychotherapy has been described as one of the most complex bio-psycho-social systems in which patterns of language, cognition, and emotion are formed and changed through the dynamics of therapist and patient interactions (Gelo and Salvatore 2016; Schiepek et al. 1992). In general,

Electronic supplementary material The online version of this article (https://doi.org/10.1007/s10608-020-10106-3) contains supplementary material, which is available to authorized users.

Travis J. Wiltshire

t.j.wiltshire@uvt.nl

1 Department of Cognitive Science and Artificial Intelligence, Tilburg University, Warandelaan 2, 5037 AB Tilburg, The Netherlands

2 Centre for Human Interactivity, Department of Language and Communication, University of Southern Denmark, Odense, Denmark research has shown that interpersonal coordination occurs during human interaction in the aforementioned modalities and in varying contexts (Butler 2011; Louwerse et al. 2012). This interpersonal coordination refers to the ways in which behavior, physiology, and emotional/cognitive states tend to covary between people over time. Increasingly, researchers have linked various forms of interpersonal coordination to important constructs and outcomes in several areas including team work (Chanel et al. 2013; Gorman 2014; Gorman et al. 2016; Guastello and Peressini 2016; Wiltshire et al. 2018), relationship science (Butler 2011; Gottman 2014; Perry et al. 2017; Randall et al. 2013), conversational dynamics (Abney et al. 2015; Fusaroli and Tylén 2016), and clinical psychology (Crowell et al. 2017; Ramseyer and Tschacher 2011, $2014,2016)$. Similarly, in psychotherapy, coordination of different interpersonal modalities and behaviors has proved important for understanding the dynamics of psychotherapeutic interaction and efficacy. For example, coordination in vocal qualities (e.g., Imel et al. 2014; Reich et al. 2014), 
bodily movements (e.g., Ramseyer and Tschacher 2011), and physiology (e.g., Marci et al. 2007) between patient and therapist have all been linked to important therapeutic processes and outcomes. Nonetheless, a coherent narrative of how interpersonal coordination relates to psychotherapeutic interaction and effectiveness remains non-extant.

Psychotherapy provides a rich context for investigating the nature of human interaction dynamics in a functionallyoriented and language-centric, collaborative context (i.e. working together toward remediation of the patient's disorder, problem, issues, etc.). Still, there are many challenges involved in understanding the functional benefits of coordination in psychotherapy as human interaction necessarily spans multiple timescales and modalities (Davis et al. 2016; Steffensen and Pedersen 2014; Tilsen 2009). By modalities, we mean what is traditionally referred to as measures derived from the human system that can be measured reliably and have potential to exhibit coordinated behavior across persons (cf. Burgoon et al. 2002), which is distinct from the traditional notion of psychotherapy modalities (Seligman 1995). Specifically, in psychotherapeutic interactions, there are patterns of coordination that emerge within and across therapy sessions as well as in various modalities including the voice, bodily movement, facial expressions, physiology, and so on. The psychotherapeutic process is both dynamic and complex because

... it comprises time-dependent biographical, historical, and developmental processes [and] because these processes are multidimensional and multidetermined, manifesting themselves in very different ways at different levels, and resulting from multiple factors reciprocally interacting with each other (p. 379, Gelo and Salvatore 2016).

While examination of interpersonal coordination in psychotherapy has been conducted in some form as far back as the 1950's (DiMascio et al. 1957), the research has been conducted quite sparsely, with various methods, and typically has focused only on particular modalities. However, due to significant advances in technologies and analytical tools over the last half century, current psychotherapy research and practice are on the cusp of significant technological change (Imel et al. 2017). Thus, a systematic review of the findings surrounding interpersonal coordination during psychotherapy is quite timely, in part, because such studies have been greatly facilitated by recent advances in technological and computational tools. Our aim with the current review is to (1) bring together into a single source all the studies that have looked at interpersonal coordination during psychotherapy to date across the available modalities, (2) assess the patterns associated with these to determine how coordination emerges during psychotherapy and relates to various psychotherapeutic processes and outcomes, and (3) provide recommendations for future research and practice on interpersonal coordination during psychotherapy. Prior to detailing the method for our systematic review, we discuss coordination and potential theory describing why it relates to therapeutic outcomes.

\section{Coordination and Psychotherapy}

Coordination is a general phenomenon that emerges in physical, biological, and psychological systems (Turvey 1990). It is the ways in which components and processes of a system change together over time (Butner et al. 2014) and it can take many forms (Butler 2011). For example, the pendulums of clocks on a wall move in time and in relative phase to each other when they share a physical medium (Strogatz and Stewart 1993), and when people swing pendula together they share oscillatory patterns and bi-directionally influence each other (Butner et al. 2005). During human interaction, there is evidence that we coordinate our movements (Abney et al. 2015), communicative behaviors (Louwerse et al. 2012), neural activity (Likens et al. 2014), physiology (Palumbo et al. 2016), and voices (Imel et al. 2014; Reich et al. 2014) with others.

Integrative approaches to psychotherapy have increasingly argued for considering psychotherapy as a dynamical system (Gelo and Salvatore 2016; Schiepek et al. 2015). The general notion here is that there is a psychotherapy system consisting of at least the patient and the therapist, each with their own sub-systems (e.g., cardiovascular, neural, etc.) that reciprocally influence each other as they interact. From this perspective, the ways in which system components coordinate are crucial for effective functioning.

While there are many plausible starting points from which to investigate psychotherapy, we focus on interpersonal coordination as a form of coordination where a variable measured from the patient and from the therapist change together in systematic ways over time. We refer to the term coordination as it is used in the field of coordination dynamics (Kelso 2009; Turvey 1990), which is superordinate to more specifically operationalized forms of coordination such as synchronization or alignment (Butner et al. 2014). Not only has there been some evidence that interpersonal coordination matters in psychotherapy in certain modalities (Ramseyer and Tschacher 2011), but there has also been more general interactional benefits of coordinating with others such as increased affiliation (Hove and Risen 2009), increased cooperative tendencies (Wiltermuth and Heath 2009), and increased prosocial behaviors and attitudes (Rennung and Göritz 2016). While there is a growing body of literature examining the benefits of interpersonal coordination, the explanation for its functionality during psychotherapy is still limited (cf. Koole and Tschacher 2016). 
One plausible explanation for why interpersonal coordination has an important role in psychotherapy is that it could be a manifestation of common factors; factors that occur in psychotherapy independent of treatment type, which have shown to be drivers of therapy effectiveness and are typically conveyed through social interaction (Messer and Wampold 2002). Relatedly, movement coordination has been associated with working alliance (Koole and Tschacher 2016) and physiological coordination has been related to empathic responding (Marci et al. 2007), both of which are often considered common factors. Furthermore, it has been argued that it is not only the working alliance that it is important, but also the 'real' relationship that is evidenced by emotional coordination between therapist and patient (Liebovitch et al. 2011; Peluso et al. 2012). In relationships broadly, there is compelling evidence for physiological co-regulation (Butler and Randall 2013), which may also apply to psychotherapeutic contexts. Another plausible explanation is polyvagal theory, which describes how coordinated physiological responding between patient and therapist may provide the bio-behavioral basis for feelings of safety that allow the therapeutic relationship to progress and flourish (Geller and Porges 2014). And, lastly, social mentality theory prescribes that in adopting a caregiving role, therapists may be biologically predisposed to attune and coregulate others in their caring/caregiving relationships (Gilbert 2019), such as those early caregiver relationships that help infants to regulate their physiology and behavior (e.g., Evans and Porter 2009; Hofer 1994). Thus, while there are a number of theoretical explanations for how interpersonal coordination may function, a systematic review of these findings in psychotherapy is warranted.

\section{Present Review}

In our review, we focus on interpersonal coordination during psychotherapeutic interactions in any modalities that have been examined including movement, physiology, vocalizations, language, and behaviors, and any psychotherapy processes or outcomes measures of coordination that the modalities have been linked with. It is our aim that an integrative set of findings on interpersonal coordination dynamics during psychotherapy can inform a richer understanding of psychotherapeutic interactions and human interaction, more broadly. In doing so, we also aim to form a basis for improving the research and practice of psychotherapy by providing some tentative recommendations for further evaluation.

\section{Method}

\section{Search and Retrieval}

We conducted a systematic literature review following existing models and guidelines (Okoli and Schabram 2010;
Palumbo et al. 2016). The goal was to retrieve all articles published in English peer-reviewed journals relating to interpersonal coordination occurring in psychotherapeutic contexts that were published no later than December 2016. An additional search was conducted on August 20, 2019. We chose our search terms based on prior literature searches and articles a priori deemed as relevant. Searches were conducted separately based on the following overarching terms: Physiological, behavioral, interpersonal, and dyadic. For each of these terms, the search algorithm was connected to the following terms with an AND statement: synchron* OR coordination OR covariation OR coherence OR linkage OR contagion OR attune* OR alignment OR mimic* AND psychotherap* OR counseling OR psychiatry. Asterisks denote that the search engine will include permutations of the specified root. Searches based on these keywords were conducted in PsychInfo and PubMed. Additionally, once articles were identified as relevant and meeting the eligibility criteria below, a reverse citation search was conducted using Google Scholar. Eligibility and exclusion criteria are listed below. Limitations of the review, by definition, are that articles outside of our search terms, time-period, or eligibility criteria were not included.

\section{Eligibility Criteria}

(1) Published in English

(2) Published in a peer-reviewed journal

(3) Empirical examination of dyadic psychotherapy sessions or interviews between patient (or pseudo-patients based on actual patients) and therapist

(4) Quantitatively assessed temporal relationships in measures collected from patient and therapist

(5) Must include behavioral and/or physiological measurements recorded at least two times during a therapy session

\section{Exclusion Criteria}

(1) Studies of psychotherapy patients if there are no analyses derived from actual sessions or interviews (e.g., if the analyses were conducted on patients performing laboratory-style tasks)

(2) Studies of couples and group therapy

(3) Examined only the coordination of responses on questionnaires

Additional details of the search and retrieval process as well as the information extracted are available upon request. Forty-three articles were included in this 
systematic review and denoted by asterisks in the References section.

\section{Results}

The results of our systematic review are framed as follows: (1) we first provide descriptive summaries of the studies to contextualize the included studies, and (2) we present the results in terms of how interpersonal coordination in the variety of observed modalities was linked to psychotherapy outcomes, processes, as well as other measures and modalities. Additionally, because not all forms of interpersonal coordination were linked to therapeutic process, outcomes, or modalities, additional text and tables organized by modality are available on an Open Science Framework repository: https://osf.io/2jz65/.

\section{Descriptive Summaries of Studies}

In the following, we provide descriptive summaries of the studies to provide an overview of the therapy types included in the studies, the gender composition of the dyads, the disorders and issues of patients, the methods used to quantify coordination, and the different timescales that were included in the analyses. Note that the values may sum to more than the total number of included articles because, for example, multiple disorders could have been included or multiple methods could have been employed.

\section{Therapy Types Summary}

The following therapy types were included in the reviewed studies: Psychodynamic therapy $(N=9)$, cognitive-behavioral psychotherapy $(N=8)$, the Hamilton Clinical Interview $(N=4)$, counseling interviews and sessions $(N=3)$, motivation interview training sessions $(N=2)$, intensive psychotherapy $(N=2)$, daily life counseling, discharge interviews, pseudo-therapy, process-oriented psychotherapy, remission interviews, psychoanalysis, psychiatric intervention cognitive-based therapy, body-oriented therapy, exposure-based therapy, and other non-specified approaches $(N=6)$ were all represented.

\section{Gender Composition Summary}

$\sim 70 \%$ of the included studies incorporated cases where there were mixed gender dyads $(N=30), \sim 11 \%$ of the studies explicitly only examined same gender dyads $(N=5)$ and $\sim 19 \%$ of the included studies did not provide enough information for us to specify the gender composition $(N=8)$.

\section{Disorders/Issues Summary}

A variety of disorders and personal issues were investigated in the studies including: depression $(N=12)$, anxiety disorder $(N=13)$, relationship issues $(N=3)$, mood disorders $(N=3)$, affective disorders $(N=3)$, adjustment disorders $(N=2)$, personality disorders $(N=3)$, personality concerns $(N=2)$, schizophrenia $(N=2)$, bipolar affective disorder $(N=2)$, somatization $(N=2)$, family problems $(N=2)$, intellectual disability $(N=1)$, interpersonal problems $(N=1)$, stress $(N=1)$, eating disorder $(N=2)$, grief/loss $(N=1)$, hostility $(N=1)$, substance abuse $(N=2)$, suicide ideation $(N=1)$, emotional issues related to health problems $(N=1)$, and pseudo-patients with no history of issues $(N=3)$, and other non-specified disorder/diagnoses $(N=8)$.

\section{Methods Summary}

Most of the studies relied on Pearson correlations of measures taken from the patients and therapists $(N=15)$. In some cases, these were traditional correlation values (e.g., DiMascio et al. 1957) and in many other cases these were ratios of positive to negative correlations derived from a windowing procedure taking time segments across the psychotherapy session (e.g., Marci and Orr 2006). A large percentage of the remaining studies relied on cross-correlations $(N=11)$, which typically quantified coordination by taking an absolute value of the cross-correlation functions across windows and at various lags (e.g., Galbusera et al. 2016; Ramseyer and Tschacher 2011). In addition, there were a number of studies that used various scores $(N=15)$ that involved calculating differences between speaking efforts (Geerts et al. 2006) or skin conductance levels (Marci et al. 2004), summing dominant behaviors of the patient and therapist (Altenstein et al. 2013), or dividing complementary behaviors of the patient by those of the therapist (Ahmed et al. 2012). Three studies used cross-recurrence quantification analysis. A variety of other quantification techniques were also used, but primarily by single studies including cohesion, multiple regression, multilevel modeling $(N=3)$, transition matrices, and cross-spectral analysis. About $28 \%(N=12)$ utilized some form of null hypothesis comparison such as surrogate or virtual pairs comparisons (Ramseyer and Tschacher 2010) or comparisons of model fit (Lord et al. 2015). 


\section{Time Scales}

Most of the studies included in this review $(N=33)$ focused on data from single sessions. Of those 33 studies, most $(N=26)$ examined only segments of a full session; the most frequently studied segments had a length of 11-15 min $(N=12)$ or $16-20 \min (N=6)$. Of the 10 studies that drew from more than one session, many of them $(N=7)$ studied a series of six sessions. Three studies drew on data from more than seven sessions, namely full psychotherapy treatment sequences consisting of 27,31 , and 44 sessions. Of these three studies, two treated each session as a singular observation in a way that does not reflect the temporal dependencies inherent to the course of treatment. Finally, one study in our sample accounted for change over time for a period longer than six sessions (Tomicic et al. 2016).

\section{Results by Coordination Function}

\section{Links to Psychotherapy Outcomes}

Interpersonal coordination in bodily movements, vocalizations, interpersonal processes, and physiology were linked to psychotherapy outcomes. Results supporting this can be found in Table 1 . Note that all outcomes not explicitly labeled session outcomes, refer to an overall outcome measure of the therapy. A majority of studies found negative associations between coordination (primarily in body movements and "Nonverbal Involvement Behavior") and symptomatology (e.g., Bos et al. 2002; Geerts et al. 1996; Ramseyer and Tschacher 2011), or a positive association with beneficial treatment outcomes such as goal attainment (Ramseyer and Tschacher 2016). This means, that stronger coordination was often associated with fewer symptoms and thus, better treatment success. In some other cases, changes toward stronger non-verbal attunement between patients and therapist within sessions or interviews were related to better responsiveness to treatment (Geerts et al. 2000) or a lowered risk for relapse (Geerts et al. 2006).

There were three findings related to vocalization that were somewhat in contrast to each other. Specifically, when the therapists' vocal pitch followed the patients' vocal pitch more strongly, an increase in symptoms was observed (Reich et al. 2014); however, when comparing a good outcome sessions to a poor outcome session, stronger coordination of speech rate between therapist and patient was associated with the better treatment outcome (Rocco et al. 2016). Moreover, another study showed that higher language style matching during early phases of treatment was associated with symptom reduction (Borelli et al. 2019). While vocal pitch, speech rate, and language style are different aspects of vocalizations, these results suggest that even within a given modality there can be variability regarding how interpersonal coordination is related to psychotherapy outcomes (i.e., associated with better or worse outcomes).

Next, references to the interpersonal processes modality explicitly refers to studies based on the interpersonal process circumplex (Wiggins 1996). While many of the other modalities could be considered interpersonal processes or behaviors, the studies included in this modality focus on those that examined relationships between displays of interpersonal control and affiliation. Generally, they examined how specific interpersonal displays were complementary and sufficiently met by matching displays. With regard to the link between psychotherapy outcomes and interpersonal processes, one study found that in cases with more successful treatment outcomes and reduction in symptoms, there was a curvilinear pattern of complementarity that started and ended high, but decreased during the middle of the treatment (Tracey et al. 1999).

Lastly, one study found that synchrony of respiration rate was associated with higher ratings by the therapist regarding the patient's progress in their treatment (Tschacher and Meier 2019).

\section{Links to Therapeutic Alliance and Relationship}

Interpersonal coordination of body movements, speech, physiology and general measures of nonverbal interpersonal processes were linked to measures of therapeutic alliance (see Table 2). In particular, the included studies linked coordination patterns of body, nonverbal affiliative behaviors, and physiology (Bar-Kalifa et al. 2019) with positive patient evaluations of therapeutic alliance (Altenstein et al. 2013; Ramseyer and Tschacher 2014, 2016; Tschacher and Meier 2019) and self-efficacy (Ramseyer and Tschacher 2011). Additionally, synchronization of body movement was negatively associated with therapist evaluation of patients' resistance (Ramseyer and Tschacher 2014).

Three studies included here examined the relation between coordination of speech and quality of therapeutic relationship. A study examining vocal pitch and quality of alliance reported that higher therapist leading was negatively associated with measures of therapeutic alliance (Reich et al. 2014). Another study investigating speech rate in a comparative case study involving two therapeutic sessions suggested a relationship between high attunement of speech rate and relationship quality (Rocco et al. 2016). Moreover, finally, another study showed a relationship between synchrony of vocal pitch (as a measure of arousal) and alliance (Bryan et al. 2018). 


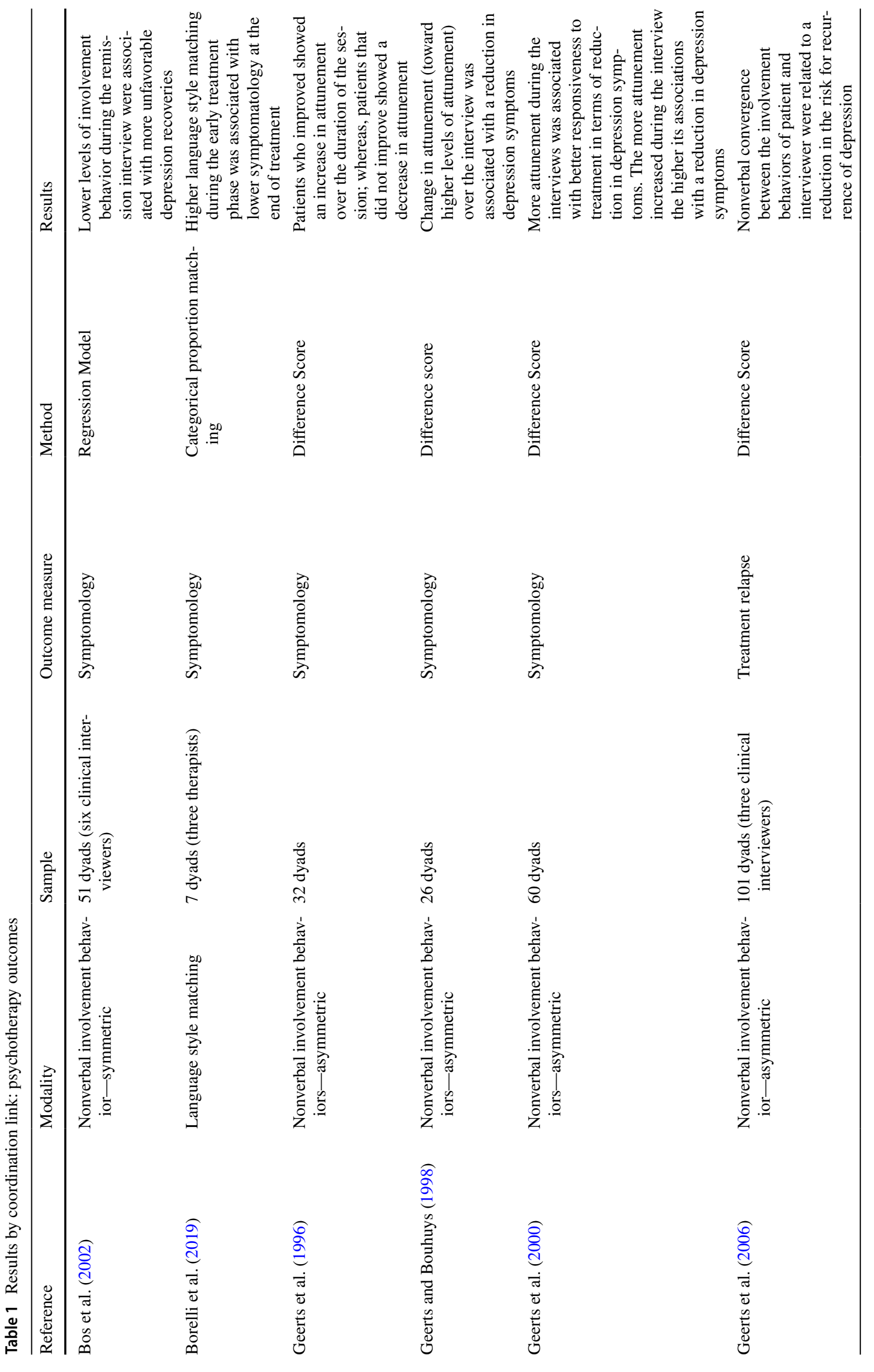




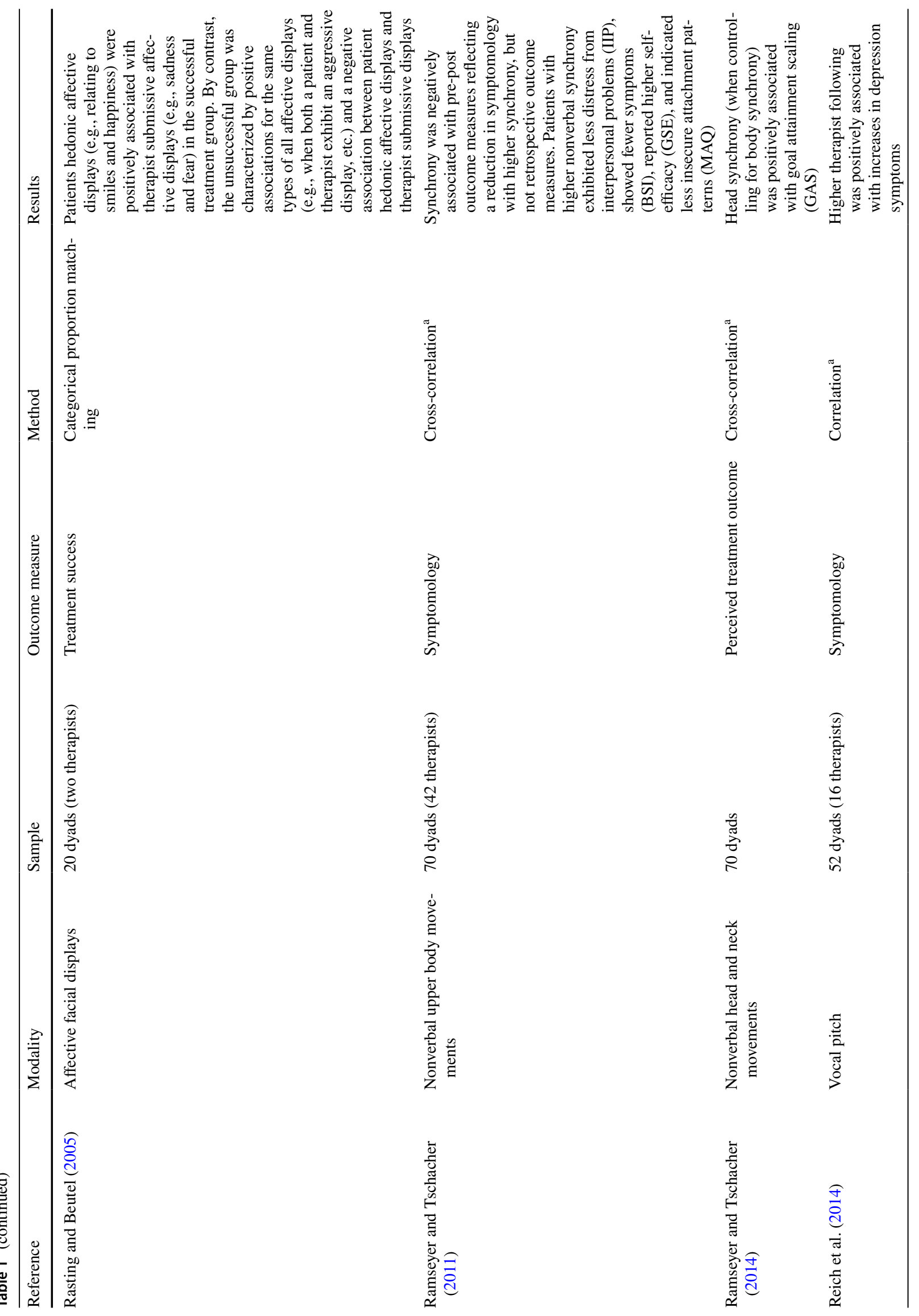




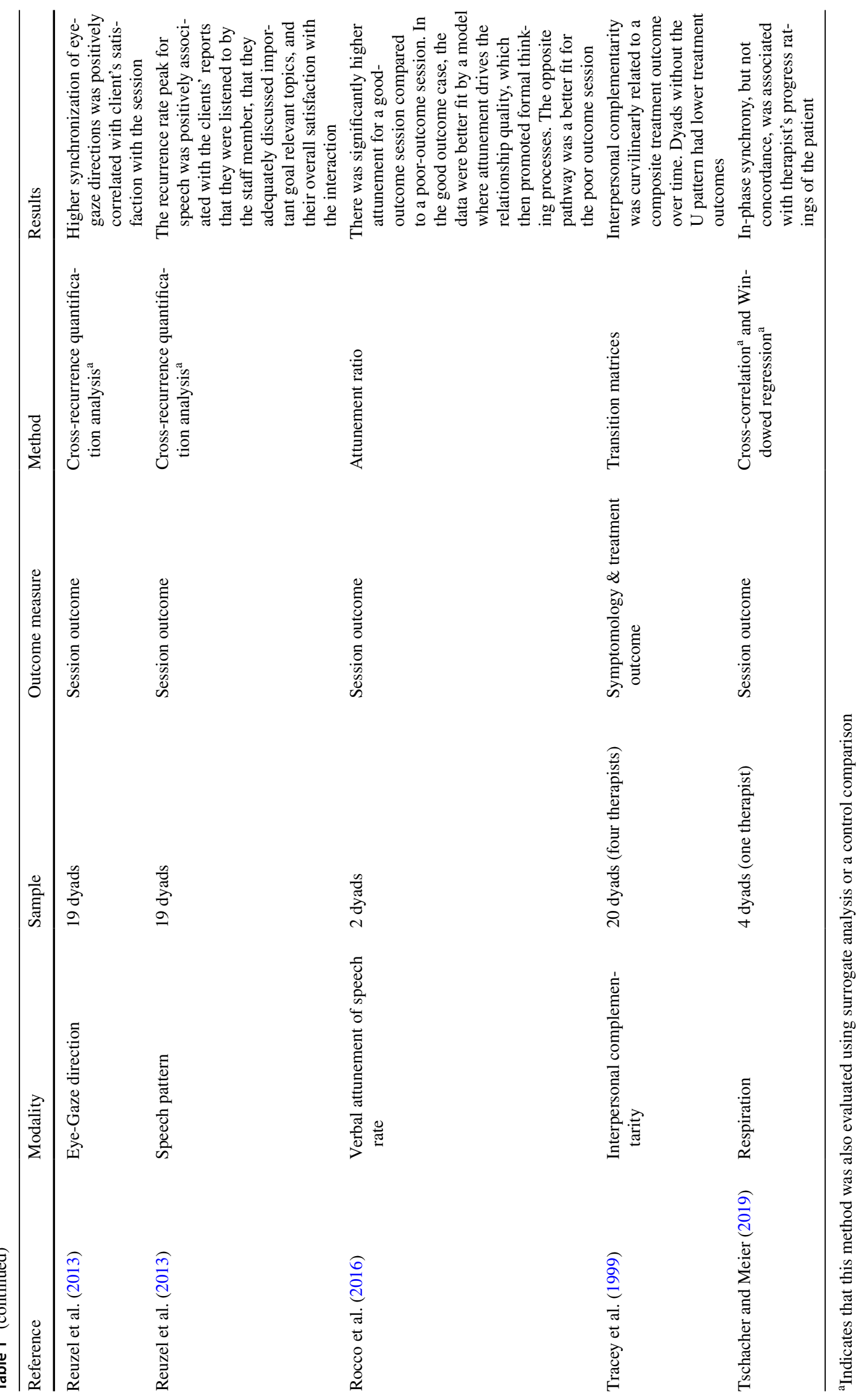




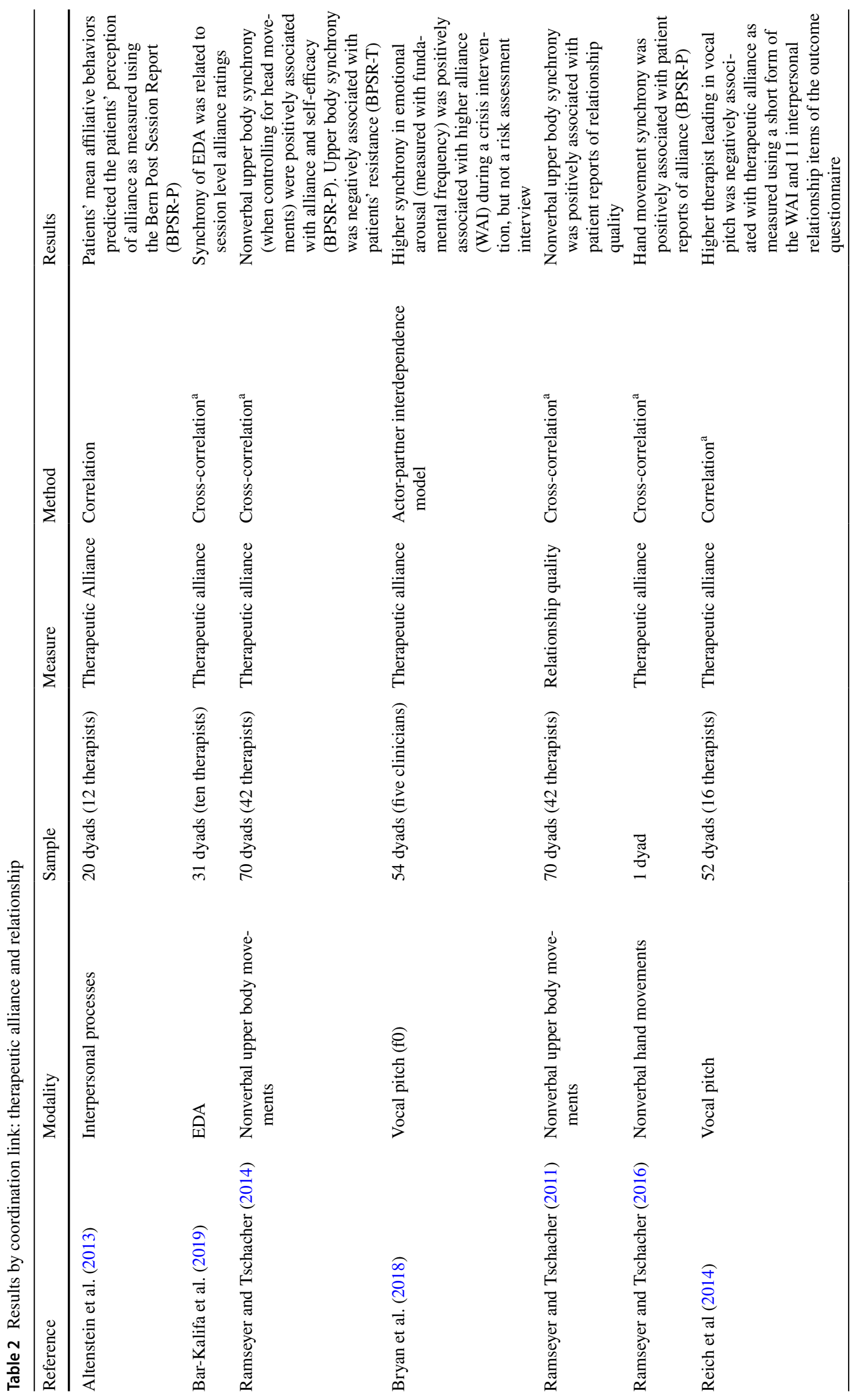




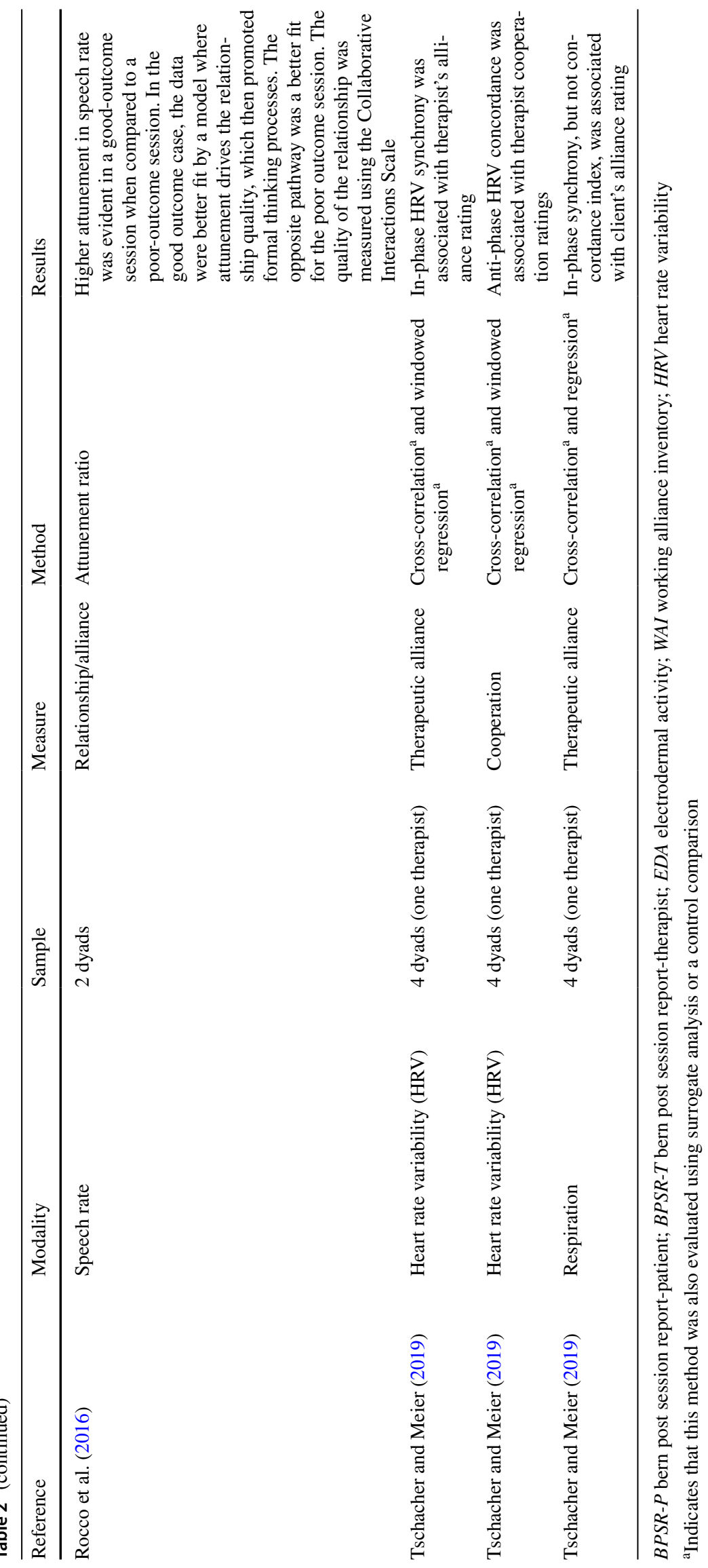




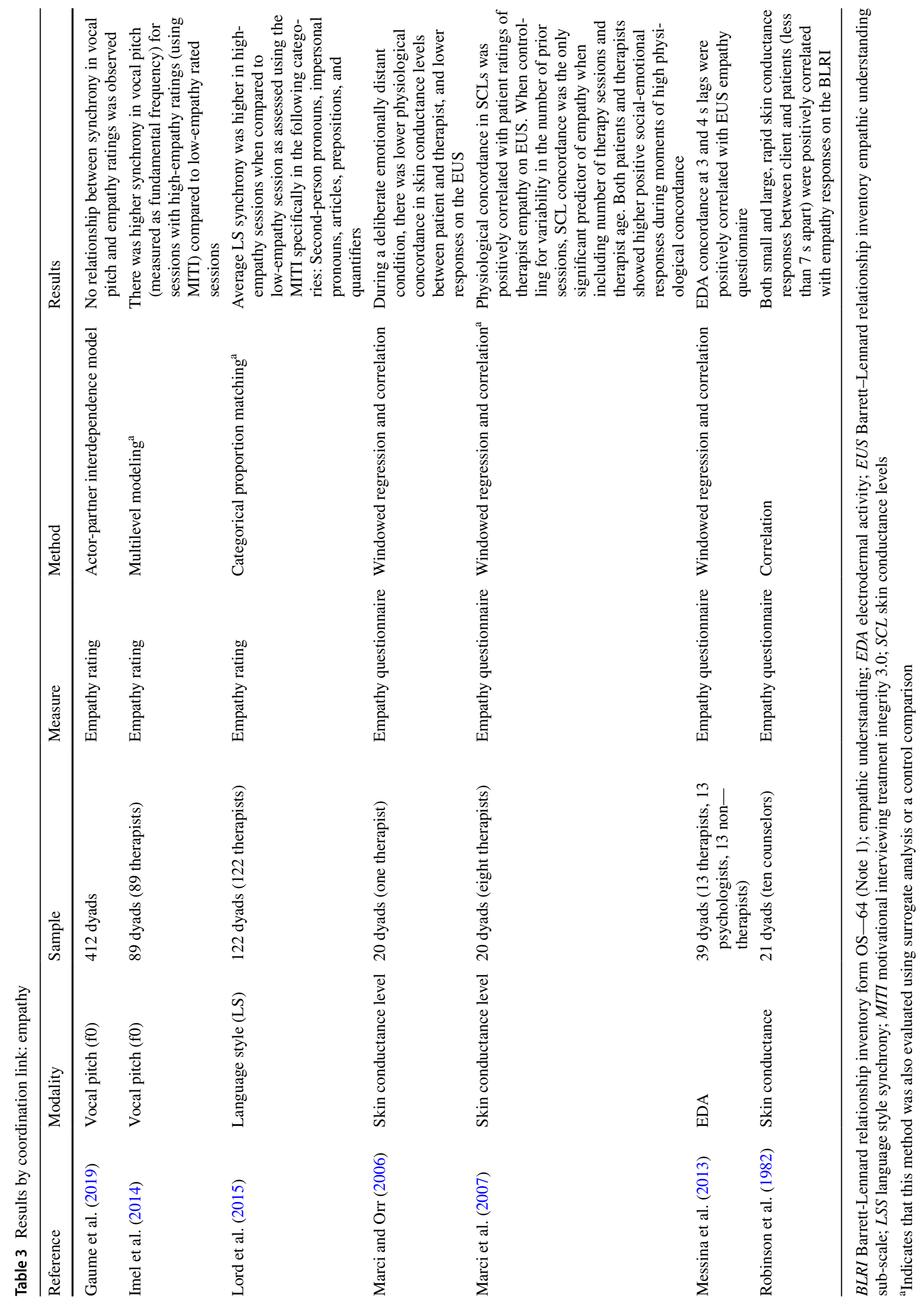




\section{Links to Empathy}

Table 3 summarizes the different ways in which measures of interpersonal coordination were related to measures of empathy. Empathy is closely linked to measures of therapeutic alliance and relationship, however, as it has been examined in isolation in some studies included in this review, we have decided to report these findings separately in the table below. For a more in-depth exploration of empathy and varying forms of emotional coordination, we refer the reader to Singer and Lamm (2009) and Butler (2011).

These studies linked measures of empathy to coordination mainly in two modalities: physiological measures (Marci et al. 2007; Marci and Orr 2006; Messina et al. 2013; Robinson et al. 1982) and coordination of voice/language (Imel et al. 2014; Lord et al. 2015). The studies reported that coordination between patient and therapists in physiological measures related to skin conductance (EDA) were associated with higher measures of empathy. Likewise, the coordination of fundamental frequency of the voice as well as the matching of particular linguistic categories between patient and therapist were associated with higher ratings of empathy (Imel et al. 2014; Lord et al. 2015), although a large replication study failed to find such an association (Gaume et al. 2019).

\section{Links Between Modalities}

A few studies investigated the coordination links between modalities. These are shown in Table 4. The dominant approach linking modalities tended to correlate physiological measures such as heart rate or skin conductance to particular patient behaviors (as coded by an observer). Taken together these results suggest that there are systematic variations in heart rate and skin conductance of both patient and therapist that correspond to particular patient behaviors such as displays of tension, tension release, hostility, antagonism, and anxiety (Coleman et al. 1956; DiMascio et al. 1957). Further, studies reported evidence of a link between coordination of "Nonverbal Involvement Behaviors" of patient and therapist that were associated with increased patient satisfaction with the interaction (Geerts et al. 2006). Two studies also examined the relationship between two physiological measures (Stratford et al. 2012, 2014) providing evidence of a relationship between neural activity and EDA as well as heart rate variability and EDA.

\section{Discussion}

In this systematic review, we set out to collate the extant findings related to interpersonal coordination in psychotherapy studies across the available interactional modalities to assess the extent to which interpersonal coordination emerges during psychotherapy and its relation to psychotherapy processes and outcomes. We found that interpersonal coordination in physiology, bodily movements, interpersonal processes, and language/speech patterns have been observed in a variety of psychotherapy contexts and further, that coordination in these modalities is related to important psychotherapeutic outcomes such as reduction in symptomatology and dropout as well as reports of therapeutic alliance and empathy. Figure 2 presents a path diagrammatic overview of our findings. There could be extant moderating or mediating relationships, although the current evidence does not allow us to predict and/or depict such relationships. Furthermore, while we draw linear relationships between the variables, this is only a schematic overview and we encourage future work to examine more complex and nonlinear relationships that may play a critical role in facilitating effective psychotherapy (Laurenceau et al. 2007).

With regard to physiology, the literature suggests that interpersonal coordination in psychotherapy emerges primarily in measures related to the autonomic nervous system such as heart rate or skin conductance. While some studies have examined neurophysiological measures such as EEG, this is not an area that has been widely explored in the psychotherapeutic context (Stratford et al. 2012). In studies that examined physiological coordination over time, no clear pattern across studies was identified except that the strength of the coordination changes both within and across sessions (Di Mascio et al. 1955; Stratford et al. 2012, 2014) and that coordination levels in early sessions may be related to diagnoses (Paulick et al. 2018b), symptom reduction (Borelli et al. 2019), and dropout (Paulick et al. 2018a). Further, physiological coordination was primarily linked to measures of empathy and emotion (Marci et al. 2007; Marci and Orr 2006; Messina et al. 2013) with no direct links between physiological coordination and psychotherapy outcomes.

Coordination in bodily movements occurred quite robustly in the included studies with both global upper bodily movements (Ramseyer and Tschacher 2011) as well as head and hand movements showing evidence of synchronization between patient and therapist (Ramseyer and Tschacher 2014, 2016). Movement coordination also appeared to matter significantly for treatment effectiveness as it had a number of associations with reductions in symptomatology, favorable treatment outcomes, and stronger therapeutic alliance (Ramseyer and Tschacher 2014, 2016). Relatedly, "Nonverbal Involvement Behaviors" and support behaviors which included measures of body movements between patient and therapist showed evidence of attunement that was also linked to reductions in symptomatology as well as reduction of relapse (Bos et al. 2002; Bouhuys and Sam 


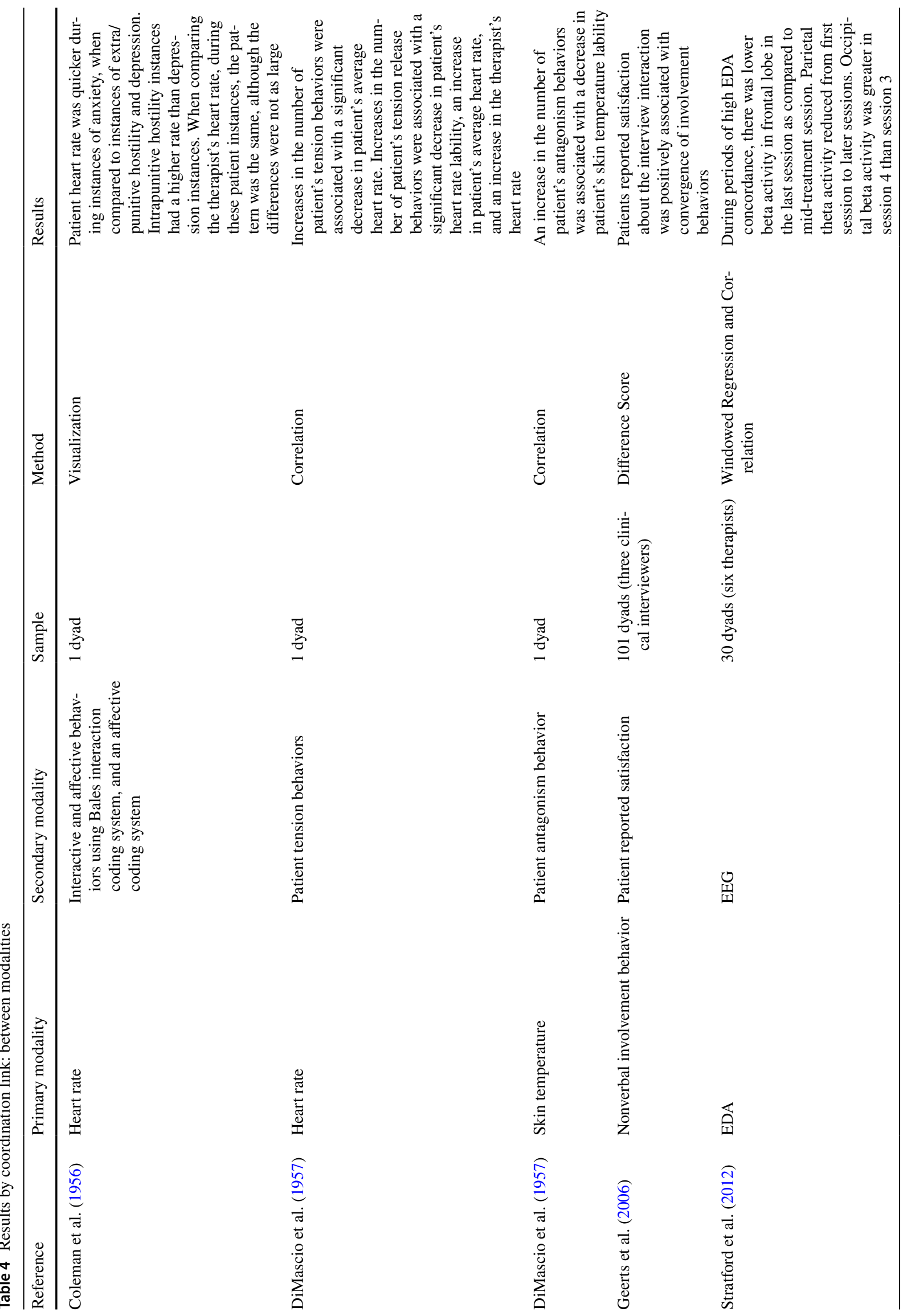




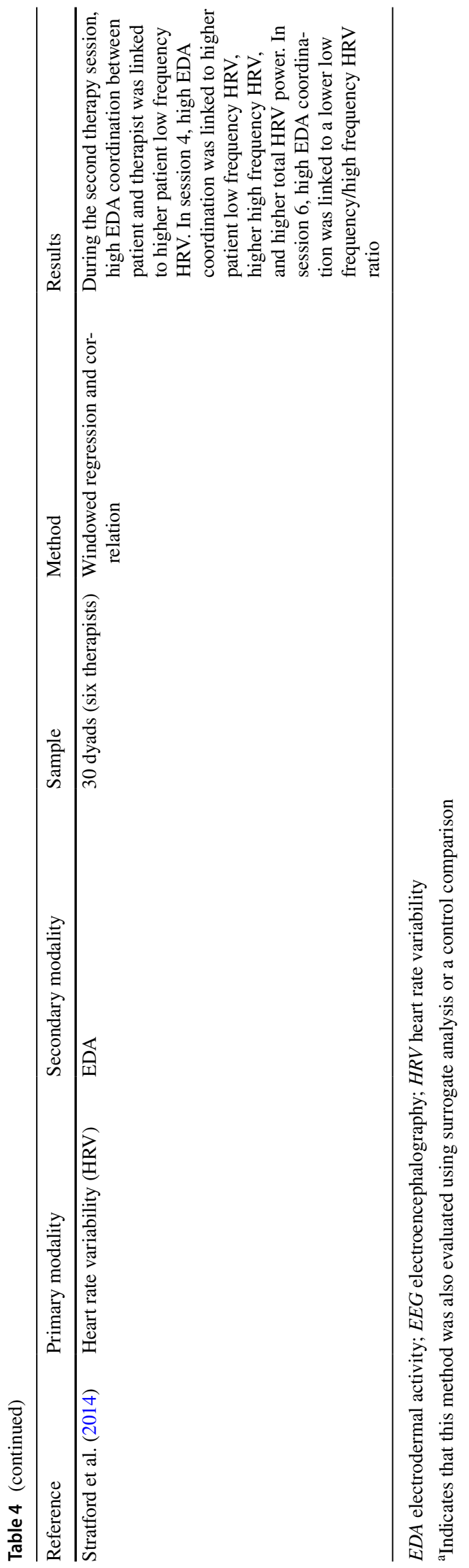

2000; Geerts and Bouhuys 1998; Geerts et al. 1996, 2000, 2006).

Additionally, interpersonal process measures derived from interpersonal theory such as displays of dominance and affiliation exhibited coordinated, yet primarily complementary patterns between patient and therapist (Ahmed et al. 2012; Thomas et al. 2014; Tracey et al. 1999); however, one study examined the reciprocity and correspondence of these constructs and how they changed over time (Altenstein et al. 2013). Complementary interpersonal processes were shown to have a link with treatment outcome. Specifically, when interpersonal complementarity exhibited a curvilinear $U$ shape over the course of treatment, patients exhibited improved treatment outcomes (Tracey et al. 1999). Additionally, the higher the average correspondence of affiliation behaviors between patient and therapist, the higher the reported therapeutic alliance (Altenstein et al. 2013).

A number of language, speech, and voice related measures exhibited coordination between patient and therapist including fundamental frequency (Imel et al. 2014; Reich et al. 2014), language style (Lord et al. 2015), vocalizationsilence dynamics (Tomicic et al. 2016), and speech rate (Rocco et al. 2016). One study showed that higher vocal pitch coordination specifically in the form of therapist leading, was associated with increases in symptoms and a reduction in therapeutic alliance (Reich et al. 2014). Another study showed that stronger attunement of speech rate between patient and therapist was related to better session outcomes and relationship quality (Rocco et al. 2016). Other work has shown that higher coordination of vocal pitch and language style was related to higher empathy ratings (Imel et al. 2014; Lord et al. 2015).

\section{General Issues and Critical Questions for Future Research}

While we have collated the extant findings on interpersonal coordination in psychotherapy, a number of critical questions remain unanswered if the aim is to explain its functionality during psychotherapy. On these grounds, we highlight a number of issues for consideration in future research. In the following, we propose four general shortcomings and three critical questions identified by this review. Note that while we refer to these as shortcomings here, we in no way diminish the value of the groundbreaking work included in this review.

\section{General Shortcomings with Extant Research}

\section{Treatment Types and Disorders/Issues}

In this review, we were quite agnostic to treatment type and patient specific disorders/issues. This is a justifiable 
approach given that interpersonal coordination as a construct is more related to common factors than particular treatments for particular conditions. Furthermore, since studies investigating interpersonal coordination in psychotherapy are relatively sparse, it is too premature to conduct a meaningful review of studies examining coordination in relation to a single treatment type or patient disorder. That being said, it is certainly an opportunity for future work to consider the role of interpersonal coordination in a variety of modalities as it functions in certain psychotherapy types and specific conditions.

\section{Methodological Shortcomings}

While there are many known methodological challenges in studying psychotherapy change processes (e.g., Laurenceau et al. 2007), such as identifying the shape of change as well as the mediators and moderators of that change, these issues are exacerbated when examining interpersonal coordination and its relationship to psychotherapeutic change and constructs. One shortcoming is that only a few of the studies heavily emphasizing cross-correlational analyses appeared to account for auto-correlation in the data, which can lead to finding spurious correlations (see Dean and Dunsmuir 2016); however, methods for surrogate testing can mitigate the chance of spurious findings (see also Kleinbub 2017 for a discussion of this shortcoming). While a number of the studies do engage in surrogate testing, this practice should be essential for ensuring that the observed coordination between patient and therapist is more than coincidence (Ramseyer and Tschacher 2010).

Another issue is the potential mismatch between construct and measurement (see also Terminological and Conceptual Shortcomings section below). Specifically, the most widely used analyses were correlational analyses, but there are other forms of coordination and corresponding analytical techniques to capture these patterns such as models that allow for varying strengths of coordination between multiple variables and different coordination ratios (Butner et al. 2014), coupled oscillations (Ferrer and Helm 2013; Ferrer et al. 2012; Fischer et al. 2017; Helm et al. 2012) that can be specific to each dyad while also generalizable (Steele et al. 2014) and specify phasic relationships (Schmidt et al. 2012), patterns of recurrence (Fusaroli et al. 2014a, b; Fusaroli and Tylén 2016), and those that assess who is driving the coordination (Crowell et al. 2017; Sugihara et al. 2012). These and other methods for assessing coordination are reviewed in detail elsewhere (e.g., Butler 2011; McAssey et al. 2013). Efforts should be taken to more clearly articulate the expected form of coordination, its relation to theoretical constructs, and appropriate methodological tools for modeling it.

\section{Terminological and Conceptual Shortcomings}

As pointed out by Palumbo et al. (2016) and Kleinbub (2017), the area of interpersonal coordination more generally, not only in psychotherapy, is rife with terminologi$\mathrm{cal}$ and conceptual problems that have contingencies with statistical and measurement issues, which in turn prohibits many cross-study comparisons (cf., Rennung and Göritz 2016). This review identifies an overall and pervasive lack of terminological consistency when it comes to referring to interpersonal coordination in psychotherapy. While a full analysis of terminology is beyond the scope of the current review, we defer to several useful papers that provide insights that span terminological and methodological uses of terms related to interpersonal coordination (see Butler 2011; Butner et al. 2014; Cornejo et al. 2017; Delaherche et al. 2012; Leclère et al. 2014; Palumbo et al. 2016).

One terminological limitation we would like to discuss is that, of the few included studies that examined phenomena related to language, a rather limited conceptualization of language was employed. As a result, much more work needs to be done in this area, and there are many potentially important conversational linguistic features such as minimal responses and hesitations, among others, that might prove crucial to examine. Semantic aspects of language that could be highly relevant to the treatment process in psychotherapy have also not yet received adequate attention. Related work, for example, has examined semantic coordination between interlocutors (Parker et al. 2016; Russell et al. 2012), particularly when there are points of change in the conversation (Wiltshire et al. 2018), and how those semantic topics change over time (Angus et al. 2012a, b; Angus et al. 2012a, b; Atkins et al. 2012).

This conceptual problem further presents itself within some frameworks included in this review that concatenate different modalities in communication collapsing measures of body movement, vocal engagement, linguistic features, eye gaze, hand gestures and so on into interpretative categories (Ahmed et al. 2012; Altenstein et al. 2013; Bos et al. 2002; Geerts and Bouhuys 1998; Geerts et al. 1996, 2000, 2006; Thomas et al. 2014; Tracey et al. 1999). Based on the results of this review, we propose that future studies investigating singular modalities ought to, rather than collapsing interpersonal, communicative, and vocalization behaviors into interpretative categories, preserve the singular modalities to advance the understanding of the ways different modalities and interactional behaviors are linked to aspects such as therapeutic alliance and symptomatology (as proposed in the first and second critical questions below). 


\section{Lack of Multi-Session Studies}

Psychotherapy is fundamentally a longitudinal process that occurs within, across, and in between many sessions. We, however, observed a tendency for studies to examine measures derived primarily from a single session. On the one hand, this makes it difficult to examine changes in therapy over time. Accordingly, we see potential in systematically investigating change in coordination over time within and across sessions. This would allow for the identification of points where there are concomitant changes in coordination in many modalities with therapeutic constructs. For example, it may be that there are expected phases to the psychotherapy (e.g., Howard et al. 1993) in which coordination is expected to change in systematic ways in particular phases. Such efforts would help to answer questions about the functional role of interpersonal coordination. Nonetheless, the ability to predict treatment outcomes with measures from a single session is of great utility; however, it leaves us with little explanation as to how and why coordination is functional in psychotherapeutic contexts, which might be garnered by studying the time course of coordination across treatment (cf. Nowak et al. 2017).

\section{Critical Questions for Future Research}

With regards to coordination of different modalities in faceto-face interaction in the context of psychotherapy, some fundamental, critical questions remain unanswered. First, an underlying question regarding the link between coordination and the quality of interpersonal relationships remains as follows: Is there a larger construct underpinning interpersonal coordination, is it capturing multiple constructs, or is coordination its own construct relevant directly for psychotherapy? For example, is coordination of movement and language underpinning the therapeutic relationship (Ramseyer and Tschacher 2011; Reich et al. 2014) and coordination in physiology capturing the 'real' emotional relationship (Peluso et al. 2012)? Or, are these constructs better reflected in the questionnaires and ratings systems designed to capture them? If the former is the case, then perhaps coordination is something that is more foundational to social interaction (Dale et al. 2013; Fusaroli et al. 2014a, b) in a way that allows these relationships to flourish (cf. Bohl 2015). Alternatively, coordination may simply be reflective of particular common factors or social mentalities and competencies associated with social roles (Gilbert 2019) or they could reflect evolutionary processes that facilitate feelings of safety in social interactions (Geller and Porges 2014). Future work that proposes changes in the relationships between these variables based on the effectiveness of the treatment may be one useful way forward for assessing the functionality of coordination in psychotherapy (Rocco et al. 2016).
Relatedly, we propose a second overall critical question regarding the link between coordination and symptomatology: What critical aspects of psychotherapy bring about change in patient behavior and symptomatology and does coordination play a role in this change? The fundamental goal of psychotherapy is to create a change in a patient's patterns of thought, behavior, and/or emotion that is remedial for a patient's disorder, problem, or concern (Wampold and Imel 2015). While this review shows a general link between coordination in some modalities and change in symptomatology, it is not clear how coordination functions toward bringing about psychotherapeutic change, particularly when the needs of clients can be so diverse. Indeed, an approach that emphasizes points of psychotherapeutic change as a basis for understanding individual psychotherapy effectiveness has been described elsewhere (Gelo and Salvatore 2016). Our emphasis on how interpersonal coordination corresponds to patterns of psychotherapeutic change could readily be incorporated into such an approach.

Finally, we propose a fundamental question that remains unanswered in the literature regarding the link between different modalities, namely: What is the relationship across modalities? While a few of the studies examined crossmodality relationships, in considering the patient and therapist as a dynamical system, there ought to be systematic relationships between measures derived from the various modalities (Gelo and Salvatore 2016; Schiepek et al. 2015). The dotted lines in Fig. 2 makes it apparent the lack of research examining relationship between modalities, and note that neurophysiological measures, to a large extent, have been unexamined. One approach to this question is exemplified in Gorman et al. (2016) who examined the relationship between neurophysiology and language styles in a teamwork context. Another example involves a study of couples therapy in which a method was advanced that links coordination in vocal pitch with physiology across three interlocutors (Butner et al. 2017). Answering this question could highlight the cascading effects that permeate the multi-scale psychotherapeutic system (cf. Kelty-Stephen et al. 2013) and highlight key modalities of influence, for example, how the behavior of one person may be driving both the behavior and physiology of another (cf. Crowell et al. 2017). This may have also practical utility in selection of important measures for actual psychotherapy sessions that are incorporated as therapeutic tools (Imel et al. 2017; Schiepek et al. 2015).

Data from a well-designed study could provide preliminary answers to these questions. Such a study would include a measure from each of the modalities included in this review (and shown in Fig. 1), each of the psychotherapy process and outcome measures, and account for longitudinal change within and across sessions. The important aspect here is that many of the studies focused only on the 


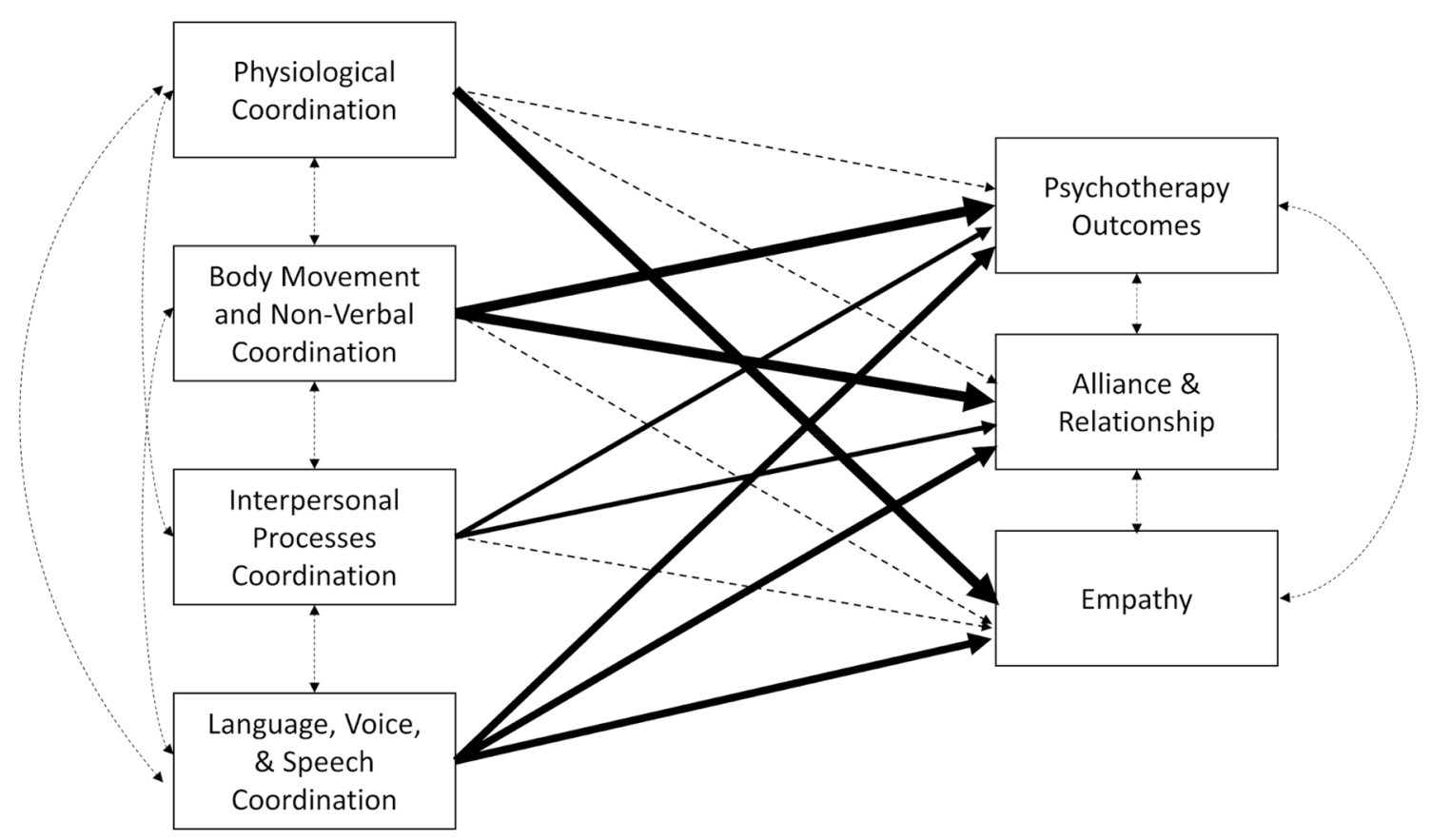

Fig. 1 Path diagram depicting summarization of study results. The thickness of the lines corresponds to the number of studies providing evidence of that relationship. Dotted lines depict relationships that were not examined in any of the reviewed studies

relationship between specific modalities with particular outcomes or processes while excluding others. While there are many valid reasons for doing so, both theoretically and pragmatically, the cost is that there are potentially important interconnections and relationships between measures that are omitted (see Fig. 1 for example), thus precluding answers to the aforementioned questions. Such a study will likely need to incorporate machine learning methods for coordination-based feature extraction across multiple measures (e.g., Chanel et al. 2013). While this type of study is a necessary precursor to the practical implications listed below, we still find the potential practical implications worth stating here as motivation for conducting such challenging, yet potentially rewarding research.

\section{Practical Implications}

All of the measures from this review can be grouped according to whether they are forms of computer- or human-based assessment (Imel et al. 2017). Whereas studies that rely on physiological measures or use automated processes to extract movement patterns from videos are examples of computer-based assessments, studies that require human responses or evaluations of behavior such as joystick ratings of interpersonal dimensions are human-based assessments. In many ways, the study of psychotherapy and longitudinal human interaction quickly becomes a big data problem where there is an increasing need for more computer-based assessments. Such methods not only allow for quicker assessments of more data, but they also open up possibilities for using technology to enhance the interaction (Imel et al. 2017). In the present context, one crucial goal involves working toward the adoption of near-real time measures of coordination, whether in bodily movements, physiology, or communication patterns, to apply meaningful feedback to the interaction itself (cf. Gorman et al. 2012; Schiepek et al. 2015; Wiltshire et al. 2020). Of course, much work remains to be done prior to advancing this effort, such as how these specific technologies can be used to scaffold specific aspects of the interaction (cf. Fiore and Wiltshire 2016; Wiltshire and Fiore 2014), although having this goal may contextualize the types of interpersonal coordination studies conducted on psychotherapy in the future.

Not only could measures of coordination become a focus for feedback during psychotherapy sessions, but perhaps first and foremost, they could become a focus for the training of psychotherapists. With all the apparent benefits of various forms of coordination, it may be a fruitful endeavor to consider what aspects of extant therapist training coincide with these findings and could be targeted as training opportunities. For example, therapists in training could undergo pitch and behavioral matching training or activities meant to align interlocutors' physiology (Ferrer and Helm 2013); or, perhaps, even dyadic practices that focus on increasing affective awareness, mentalization capacities (Singer and Engert 2019), and neurofeedback that encourages empathy (Järvelä 
et al. 2019). Activities of this nature, while not substitutes for current forms of training, may give therapists additional interactional strategies that allow them to become more aware of the ways in which they coordinate with patients, which in turn, may contribute to better psychotherapeutic outcomes. The benefits of such training remain to be seen, although there is reasonable motivation to explore these possibilities given the extant findings.

Advancing the empirical work in this area will have practical implications for theory building as well. On the one hand, these studies show that coordination matters in psychotherapy, but studies in other contexts are beginning to show that more coordination is not necessarily better and may be largely contingent upon context (Abney et al. 2015; Miles et al. 2017; Timmons et al. 2015). It may be that better therapeutic outcomes are achieved with an optimum amount of coordination (cf. Harrison and Stergiou 2015; Ramseyer 2011; Wiltshire et al. 2018) that occurs at the right time and that is in a specific modality or at the right level of analysis (Koole and Tschacher 2016). In some cases, the optimum coordination, may in fact be no coordination at all to achieve a specific interaction/therapeutic goal including, for example, interpersonal dynamics that temporarily rupture the therapeutic relationship (e.g., Colli and Lingiardi 2009). Such efforts to identify more nuanced aspects of interpersonal coordination as they relate to the particular needs of the client, different therapeutic contexts, diagnoses, personality traits, and personal/therapeutic/interactional goals, will contribute more largely to understanding and enriching theory about interpersonal coordination during human interaction.

\section{Conclusion}

Interpersonal coordination plays a functional role in psychotherapy, yet that role is not widely understood. As a first attempt at clarifying this relationship, we have reviewed the extant studies on interpersonal coordination occurring in psychotherapeutic contexts. We showed that there is evidence of coordination in bodily movement, voice, language, and physiology during psychotherapy and that these modalities differentially relate to treatment outcomes, relationship quality, and empathy. At least in the studies conducted so far, we found that movement coordination was most associated with psychotherapy outcomes, physiological coordination was most associated with empathy, and coordination in a variety of modalities including language/vocalizations were associated with therapeutic alliance. While this area shows promise for contributing to a better understanding of psychotherapy and human interaction, there is much work needed to better illuminate the relationship between coordination and psychotherapeutic outcomes and processes. This review is an essential first step towards unifying the disparate findings in this area and identifying the critical questions that will guide this field of inquiry, hopefully, for years to come.

Acknowledgements We wish to thank Kirsten Abild Nielsen, Nadine Kirstine Lund Hollmann, and Line Juncker Kjærsgaard for their assistance with the literature review process. Also, we wish to thank Marlene Skovgaard Lyby as well as three anonymous reviewers for their helpful comments on a draft of this manuscript. This work was supported by the Velux Foundations [Grant Number 10384] and the Carlsberg Foundation [Grant Number CF16-0455].

\section{Compliance with Ethical Standards}

Conflict of interest All authors declare that they have no conflict of interest.

Research Involving Human and Rights This work and it involved no human or animal participants.

Open Access This article is licensed under a Creative Commons Attribution 4.0 International License, which permits use, sharing, adaptation, distribution and reproduction in any medium or format, as long as you give appropriate credit to the original author(s) and the source, provide a link to the Creative Commons licence, and indicate if changes were made. The images or other third party material in this article are included in the article's Creative Commons licence, unless indicated otherwise in a credit line to the material. If material is not included in the article's Creative Commons licence and your intended use is not permitted by statutory regulation or exceeds the permitted use, you will need to obtain permission directly from the copyright holder. To view a copy of this licence, visit http://creativecommons.org/licenses/by/4.0/.

\section{References}

Abney, D. H., Paxton, A., Dale, R., \& Kello, C. T. (2015). Movement dynamics reflect a functional role for weak coupling and role structure in dyadic problem solving. Cognitive Processing, 16(4), 325-332.

*Ahmed, M., Westra, H. A., \& Constantino, M. J. (2012). Early therapy interpersonal process differentiating clients high and low in outcome expectations. Psychotherapy Research, 22(6), 731-745.

*Altenstein, D., Krieger, T., \& Grosse Holtforth, M. (2013). Interpersonal microprocesses predict cognitive-emotional processing and the therapeutic alliance in psychotherapy for depression. Journal of Counseling Psychology, 60(3), 445-452.

Angus, D., Smith, A., \& Wiles, J. (2012a). Conceptual recurrence plots: Revealing patterns in human discourse. IEEE transactions on Visualization and Computer Graphics, 18(6), 988-997.

Angus, D., Watson, B., Smith, A., Gallois, C., \& Wiles, J. (2012b). Visualising conversation structure across time: Insights into effective doctor-patient consultations. PLoS ONE, 7(6), e38014.

Atkins, D. C., Rubin, T. N., Steyvers, M., Doeden, M. A., Baucom, B. R., \& Christensen, A. (2012). Topic models: A novel method for modeling couple and family text data. Journal of Family Psychology, 26(5), 816-827.

*Bar-Kalifa, E., Prinz, J. N., Atzil-Slonim, D., Rubel, J. A., Lutz, W., \& Rafaeli, E. (2019). Physiological synchrony and therapeutic alliance in an imagery-based treatment. Journal of Counseling Psychology, 66(4), 508-517. 
Bohl, V. (2015). We read minds to shape relationships. Philosophical Psychology, 28(5), 674-694.

*Borelli, J. L., Sohn, L., Wang, B. A., Hong, K., DeCoste, C., \& Suchman, N. E. (2019). Therapist-client language matching: Initial promise as a measure of therapist-client relationship quality. Psychoanalytic Psychology, 36(1), 9-18.

*Bos, E. H., Geerts, E., \& Bouhuys, A. L. (2002). Non-verbal interaction involvement as an indicator of prognosis in remitted depressed subjects. Psychiatry Research, 113(3), 269-277.

*Bouhuys, A., \& Sam, M. (2000). Lack of coordination of nonverbal behaviour between patients and interviewers as a potential risk factor to depression recurrence: Vulnerability accumulation in depression. Journal of Affective Disorders, 57(1), 189-200.

*Bryan, C. J., Baucom, B. R., Crenshaw, A. O., Imel, Z., Atkins, D. C., Clemans, T. A., ..., Rudd, M. D. (2018). Associations of patient-rated emotional bond and vocally encoded emotional arousal among clinicians and acutely suicidal military personnel. Journal of Consulting and Clinical Psychology, 86(4), 372-383.

Burgoon, J. K., Bonito, J. A., Ramirez, A., Dunbar, N. E., Kam, K., \& Fischer, J. (2002). Testing the interactivity principle: Effects of mediation, propinquity, and verbal and nonverbal modalities in interpersonal interaction. Journal of Communication, 52(3), 657-677.

Butler, E. A. (2011). Temporal interpersonal emotion systems: The "TIES" that form relationships. Personality and Social Psychology Review, 15(4), 367-393.

Butler, E. A., \& Randall, A. K. (2013). Emotional coregulation in close relationships. Emotion Review, 5(2), 202-210.

Butner, J. E., Amazeen, P. G., \& Mulvey, G. M. (2005). Multilevel modeling of two cyclical processes: Extending differential structural equation modeling to nonlinear coupled systems. Psychological Methods, 10(2), 159-177.

Butner, J. E., Berg, C. A., Baucom, B. R., \& Wiebe, D. J. (2014). Modeling coordination in multiple simultaneous latent change scores. Multivariate Behavioral Research, 49(6), 554-570.

Butner, J. E., Deits-Lebehn, C., Crenshaw, A. O., Wiltshire, T. J., Perry, N. S., Kent de Grey, R. G., ..., Baucom, B. R. (2017). A multivariate dynamic systems model for psychotherapy with more than one client. Journal of Counseling Psychology, 64(6), 616-625.

Chanel, G., Bétrancourt, M., Pun, T., Cereghetti, D., \& Molinari, G. (2013, September). Assessment of computer-supported collaborative processes using interpersonal physiological and eyemovement coupling. In Affective Computing and Intelligent Interaction (ACII), 2013 Humaine Association Conference on (pp. 116-122). IEEE.

*Coleman, R., Greenblatt, M., \& Solomon, H. C. (1956). Physiological evidence of rapport during psychotherapeutic interviews. Diseases of the Nervous System, 17(3), 71-77.

Colli, A., \& Lingiardi, V. (2009). The Collaborative Interactions Scale: A new transcript-based method for the assessment of therapeutic alliance ruptures and resolutions in psychotherapy. Psychotherapy Research, 19(6), 718-734.

Crowell, S. E., Butner, J. E., Wiltshire, T. J., Munion, A. K., Yaptangco, M., \& Beauchaine, T. P. (2017). Evaluating emotional and biological sensitivity to maternal behavior among self-injuring and depressed adolescent girls using nonlinear dynamics. Clinical Psychological Science, 5(2), 272-285.

Dale, R., Fusaroli, R., Duran, N., \& Richardson, D. C. (2013). The self-organization of human interaction. Psychology of Learning and Motivation, 59, 43-95.

Davis, T. J., Brooks, T. R., \& Dixon, J. A. (2016). Multi-scale interactions in interpersonal coordination. Journal of Sport and Health Science, 5(1), 25-34.
Dean, R. T., \& Dunsmuir, W. T. (2016). Dangers and uses of crosscorrelation in analyzing time series in perception, performance, movement, and neuroscience: The importance of constructing transfer function autoregressive models. Behavior Research Methods, 48(2), 783-802.

Delaherche, E., Chetouani, M., Mahdhaoui, A., Saint-Georges, C., Viaux, S., \& Cohen, D. (2012). Interpersonal synchrony: A survey of evaluation methods across disciplines. IEEE Transactions on Affective Computing, 3(3), 349-365.

*Di Mascio, A., Boyd, R. W., Greenblatt, M., \& Solomon, H. C. (1955). The psychiatric interview: A sociophysiologic study. Diseases of the Nervous System, 16(1), 4-9.

*DiMascio, A., Boyd, R. W., \& Greenblatt, M. (1957). Physiological correlates of tension and antagonism during psychotherapy: A study of" Interpersonal Physiology". Psychosomatic Medicine, 19(2), 99-104.

Evans, C. A., \& Porter, C. L. (2009). The emergence of mother-infant co-regulation during the first year: Links to infants' developmental status and attachment. Infant Behavior and Development, $32(2), 147-158$.

Ferrer, E., \& Helm, J. L. (2013). Dynamical systems modeling of physiological coregulation in dyadic interactions. International Journal of Psychophysiology, 88(3), 296-308.

Ferrer, E., Steele, J. S., \& Hsieh, F. (2012). Analyzing the dynamics of affective dyadic interactions using patterns of intra-and interindividual variability. Multivariate Behavioral Research, 47(1), 136-171.

Fiore, S. M., \& Wiltshire, T. J. (2016). Technology as teammate: Examining the role of external cognition in support of team cognitive processes. Frontiers in Psychology, 7(1531), 1-17.

Fischer, M. S., Baucom, D. H., Baucom, B. R., Abramowitz, J. S., Kirby, J. S., \& Bulik, C. M. (2017). Disorder-specific patterns of emotion coregulation in couples: Comparing obsessive compulsive disorder and anorexia nervosa. Journal of Family Psychology, 31(3), 304-315.

Fusaroli, R., Konvalinka, I., \& Wallot, S. (2014a). Analyzing social interactions: The promises and challenges of using cross recurrence quantification analysis. In T. Recurrences (Ed.), Webber, $C$ (pp. 137-155). Cham: Springer.

Fusaroli, R., Rączaszek-Leonardi, J., \& Tylén, K. (2014b). Dialog as interpersonal synergy. New Ideas in Psychology, 32, 147-157.

Fusaroli, R., \& Tylén, K. (2016). Investigating conversational dynamics: Interactive alignment, Interpersonal synergy, and collective task performance. Cognitive Science, 40(1), 145-171.

*Galbusera, L., Finn, M. T., \& Fuchs, T. (2016). Interactional synchrony and negative symptoms: An outcome study of body-oriented psychotherapy for schizophrenia. Psychotherapy Research, 28(3), 457-469.

*Gaume, J., Hallgren, K. A., Clair, C., Schmid Mast, M., Carrard, V., \& Atkins, D. C. (2019). Modeling empathy as synchrony in clinician and patient vocally encoded emotional arousal: A failure to replicate. Journal of Counseling Psychology, 66(3), 341-350.

*Geerts, E., \& Bouhuys, N. (1998). Multi-level prediction of short-term outcome of depression: Non-verbal interpersonal processes, cognitions and personality traits. Psychiatry Research, 79(1), 59-72.

*Geerts, E., Bouhuys, N., \& Van den Hoofdakker, R. H. (1996). Nonverbal attunement between depressed patients and an interviewer predicts subsequent improvement. Journal of Affective Disorders, $40(1), 15-21$.

*Geerts, E., Kouwert, E., Bouhuys, N., Meesters, Y., \& Jansen, J. (2000). Nonverbal interpersonal attunement and extravert personality predict outcome of light treatment in seasonal affective disorder. Journal of Affective Disorders, 59(3), 193-204.

*Geerts, E., van Os, T., Ormel, J., \& Bouhuys, N. (2006). Nonverbal behavioral similarity between patients with depression in 
remission and interviewers in relation to satisfaction and recurrence of depression. Depression and Anxiety, 23(4), 200-209.

Geller, S. M., \& Porges, S. W. (2014). Therapeutic presence: Neurophysiological mechanisms mediating feeling safe in therapeutic relationships. Journal of Psychotherapy Integration, 24(3), 178-192.

Gelo, O. C. G., \& Salvatore, S. (2016). A dynamic systems approach to psychotherapy: A meta-theoretical framework for explaining psychotherapy change processes. Journal of Counseling Psychology, 63(4), 379-395.

Gilbert, P. (2019). Psychotherapy for the 21st Century: An integrative, evolutionary, contextual, biopsychosocial approach. Psychology and Psychotherapy: Theory, Research and Practice, 92(2), 164-189.

Gorman, J. C. (2014). Team coordination and dynamics: Two central issues. Current Directions in Psychological Science, 23(5), 355-360.

Gorman, J. C., Hessler, E. E., Amazeen, P. G., Cooke, N. J., \& Shope, S. M. (2012). Dynamical analysis in real time: Detecting perturbations to team communication. Ergonomics, 55(8), 825-839.

Gorman, J. C., Martin, M. J., Dunbar, T. A., Stevens, R. H., Galloway, T. L., Amazeen, P. G., et al. (2016). Cross-level effects between neurophysiology and communication during team training. Human Factors: The Journal of the Human Factors and Ergonomics Society, 58(1), 181-199.

Gottman, J. M. (2014). Principia amoris: The new science of love. New York: Routledge.

Guastello, S. J., \& Peressini, A. F. (2016). Development of a synchronization coefficient for biosocial interactions in groups and teams. Small Group Research, 48(1), 3-33.

Harrison, S. J., \& Stergiou, N. (2015). Complex adaptive behavior and dexterous action. Nonlinear Dynamics, Psychology, and Life Sciences, 19(4), 345-394.

Helm, J. L., Sbarra, D., \& Ferrer, E. (2012). Assessing cross-partner associations in physiological responses via coupled oscillator models. Emotion, 12(4), 748-762.

Hofer, M. A. (1994). Early relationships as regulators of infant physiology and behavior. Acta Paediatrica, 83, 9-18.

Hove, M. J., \& Risen, J. L. (2009). It's all in the timing: Interpersonal synchrony increases affiliation. Social Cognition, 27(6), 949-960.

Howard, K. I., Lueger, R. J., Maling, M. S., \& Martinovich, Z. (1993). A phase model of psychotherapy outcome: Causal mediation of change. Journal of Consulting and Clinical Psychology, 61(4), 678-685.

*Imel, Z. E., Barco, J. S., Brown, H. J., Baucom, B. R., Baer, J. S., Kircher, J. C., et al. (2014). The association of therapist empathy and synchrony in vocally encoded arousal. Journal of Counseling Psychology, 61(1), 146-153.

Imel, Z. E., Caperton, D. D., Tanana, M., \& Atkins, D. C. (2017). Technology-enhanced human interaction in psychotherapy. Journal of Counseling Psychology, 64(4), 385-393.

Järvelä, S., Salminen, M., Ruonala, A., Timonen, J., Mannermaa, K., Ravaja, N., \& Jacucci, G. (2019, January). DYNECOM: Augmenting empathy in VR with dyadic synchrony neurofeedback. In Proceedings of the 52nd Hawaii International Conference on System Sciences, pp. 4212-4220

Kelso, J. A. (2009). Coordination dynamics. In R. A. Meyers (Ed.), Encyclopedia of Complexity and systems science (pp. 15371565). New York: Springer.

Kelty-Stephen, D. G., Palatinus, K., Saltzman, E., \& Dixon, J. A. (2013). A tutorial on multifractality, cascades, and interactivity for empirical time series in ecological science. Ecological Psychology, 25(1), 1-62.
Kleinbub, J. R. (2017). State of the art of interpersonal physiology in psychotherapy: A systematic review. Frontiers in Psychology, 8(2053), 1-10.

Koole, S. L., \& Tschacher, W. (2016). Synchrony in psychotherapy: A review and an integrative framework for the therapeutic alliance. Frontiers in Psychology, 7(862), 1-17.

*Kykyri, V.-L., Karvonen, A., Wahlström, J., Kaartinen, J., Penttonen, M., \& Seikkula, J. (2017). Soft prosody and embodied attunement in therapeutic interaction: A multimethod case study of a moment of change. Journal of Constructivist Psychology, 30(3), 271-234.

Laurenceau, J.-P., Hayes, A. M., \& Feldman, G. C. (2007). Some methodological and statistical issues in the study of change processes in psychotherapy. Clinical Psychology Review, 27(6), 682-695.

Leclère, C., Viaux, S., Avril, M., Achard, C., Chetouani, M., Missonnier, S., et al. (2014). Why synchrony matters during motherchild interactions: A systematic review. PLoS ONE, 9(12), 1-34.

Liebovitch, L. S., Peluso, P. R., Norman, M. D., Su, J., \& Gottman, J. M. (2011). Mathematical model of the dynamics of psychotherapy. Cognitive Neurodynamics, 5(3), 265-275.

Likens, A. D., Amazeen, P. G., Stevens, R., Galloway, T., \& Gorman, J. C. (2014). Neural signatures of team coordination are revealed by multifractal analysis. Social Neuroscience, 9(3), 219-234.

*Lord, S. P., Sheng, E., Imel, Z. E., Baer, J., \& Atkins, D. C. (2015). More than reflections: Empathy in motivational interviewing includes language style synchrony between therapist and client. Behavior Therapy, 46(3), 296-303.

Louwerse, M. M., Dale, R., Bard, E. G., \& Jeuniaux, P. (2012). Behavior matching in multimodal communication is synchronized. Cognitive Science, 36(8), 1404-1426.

*Marci, C. D., Ham, J., Moran, E., \& Orr, S. P. (2007). Physiologic correlates of perceived therapist empathy and social-emotional process during psychotherapy. The Journal of Nervous and Mental Disease, 195(2), 103-111.

*Marci, C. D., Moran, E. K., \& Orr, S. P. (2004). Physiologic evidence for the interpersonal role of laughter during psychotherapy. The Journal of Nervous and Mental Disease, 192(10), 689-695.

*Marci, C. D., \& Orr, S. P. (2006). The effect of emotional distance on psychophysiologic concordance and perceived empathy between patient and interviewer. Applied Psychophysiology and Biofeedback, 31(2), 115-128.

McAssey, M. P., Helm, J., Hsieh, F., Sbarra, D. A., \& Ferrer, E. (2013). Methodological advances for detecting physiological synchrony during dyadic interactions. Methodology, 9(2), 41-53.

Messer, S. B., \& Wampold, B. E. (2002). Let's face facts: Common factors are more potent than specific therapy ingredients. Clinical Psychology: Science and Practice, 9(1), 21-25.

*Messina, I., Palmieri, A., Sambin, M., Kleinbub, J. R., Voci, A., \& Calvo, V. (2013). Somatic underpinnings of perceived empathy: The importance of psychotherapy training. Psychotherapy Research, 23(2), 169-177.

Miles, L. K., Lumsden, J., Flannigan, N., Allsop, J. S., \& Marie, D. (2017). Coordination matters: Interpersonal synchrony influences collaborative problem-solving. Psychology, 8(11), 1857-1878.

Nowak, A., Vallacher, R. R., Zochowski, M., \& Rychwalska, A. (2017). Functional synchronization: The emergence of coordinated activity in human systems. Frontiers in Psychology, 8(945), 1-15.

Okoli, C., \& Schabram, K. (2010). A guide to conducting a systematic literature review of information systems research. Sprouts: Working Papers on Information Systems, 10(26), 1-49.

*Orsucci, F. F., Musmeci, N., Aas, B., Schiepek, G., Reda, M. A., Canestri, L., de Felice, G. (2016). Synchronization analysis of language and physiology in human dyads. Nonlinear Dynamics, Psychology, and Life Sciences, 20(2), 167-191. 
*Palmieri, A., Kleinbub, J. R., Calvo, V., Benelli, E., Messina, I., Sambin, M., et al. (2018). Attachment-security prime effect on skinconductance synchronization in psychotherapists: An empirical study. Journal of Counseling Psychology, 65(4), 490-499.

Palumbo, R. V., Marraccini, M. E., Weyandt, L. L., Wilder-Smith, O., McGee, H. A., Liu, S., et al. (2016). Interpersonal autonomic physiology A systematic review of the literature. Personality and Social Psychology Review, 21(2), 99-141.

Parker, J., Best, C., Funke, G., Strang, A., \& Marion, K. (2016, September). An investigation of coding schemes for sample entropy analysis of communications data. In Proceedings of the Human Factors and Ergonomics Society Annual Meeting (Vol. 60, No. 1, pp. 111-115). Los Angeles, CA: Sage.

*Paulick, J., Deisenhofer, A. K., Ramseyer, F., Tschacher, W., Boyle, K., Rubel, J., et al. (2018a). Nonverbal synchrony: A new approach to better understand psychotherapeutic processes and drop-out. Journal of Psychotherapy Integration, 28(3), 367-384.

*Paulick, J., Rubel, J. A., Deisenhofer, A. K., Schwartz, B., Thielemann, D., Altmann, U., ..., Lutz, W. (2018b). Diagnostic features of nonverbal synchrony in psychotherapy: Comparing depression and anxiety. Cognitive Therapy and Research, 42(5), 539-551.

Peluso, P. R., Liebovitch, L. S., Gottman, J. M., Norman, M. D., \& Su, J. (2012). A mathematical model of psychotherapy: An investigation using dynamic non-linear equations to model the therapeutic relationship. Psychotherapy Research, 22(1), 40-55.

Perry, N. S., Baucom, K. J., Bourne, S., Butner, J., Crenshaw, A. O., Hogan, J. N., ..., Baucom, B. R. (2017). Graphic methods for interpreting longitudinal dyadic patterns from repeated-measures actor-partner interdependence models. Journal of Family Psychology, 31(5), 592-603.

Ramseyer, F. (2011). Nonverbal synchrony in psychotherapy: Embodiment at the level of the dyad. In W. Tschacher \& C. Bergomi (Eds.), The implications of embodiment: Cognition and communication (pp. 193-207). Exeter: Imprint Academic.

Ramseyer, F., \& Tschacher, W. (2010). Nonverbal synchrony or random coincidence? How to tell the difference. In A. Esposito, N. Campbell, C. Vogel, A. Hussain, \& A. Nijholt (Eds.), Development of multimodal interfaces: Active listening and synchrony (pp. 182-196). Berlin: Springer.

*Ramseyer, F., \& Tschacher, W. (2011). Nonverbal synchrony in psychotherapy: Coordinated body movement reflects relationship quality and outcome. Journal of Consulting and Clinical Psychology, 79(3), 284-295.

*Ramseyer, F., \& Tschacher, W. (2014). Nonverbal synchrony of headand body-movement in psychotherapy: Different signals have different associations with outcome. Frontiers in Psychology, 5(979), 1-8

*Ramseyer, F., \& Tschacher, W. (2016). Movement coordination in psychotherapy: Synchrony of hand movements is associated with session outcome. A single-case study. Nonlinear Dynamics, Psychology, and Life Sciences, 20(2), 145-166.

Randall, A. K., Post, J. H., Reed, R. G., \& Butler, E. A. (2013). Cooperating with your romantic partner: Associations with interpersonal emotion coordination. Journal of Social and Personal Relationships, 30(8), 1072-1095.

*Rasting, M., \& Beutel, M. E. (2005). Dyadic affective interactive patterns in the intake interview as a predictor of outcome. Psychotherapy Research, 15(3), 188-198.

*Reich, C. M., Berman, J. S., Dale, R., \& Levitt, H. M. (2014). Vocal synchrony in psychotherapy. Journal of Social and Clinical Psychology, 33(5), 481-494.

Rennung, M., \& Göritz, A. S. (2016). Prosocial consequences of interpersonal synchrony: A meta-analysis. Zeitschrift für Psychologie, 224(3), 168-189.
*Reuzel, E., Embregts, P. J., Bosman, A. M., Cox, R., van Nieuwenhuijzen, M., \& Jahoda, A. (2013). Conversational synchronization in naturally occurring settings: A recurrence-based analysis of gaze directions and speech rhythms of staff and clients with intellectual disability. Journal of Nonverbal Behavior, 37(4), 281-305.

*Robinson, J. W., Herman, A., \& Kaplan, B. J. (1982). Autonomic responses correlate with counselor-client empathy. Journal of Counseling Psychology, 29(2), 195-198.

*Rocco, D., Gennaro, A., Salvatore, S., Stoycheva, V., \& Bucci, W. (2016). Clinical mutual attunement and the development of therapeutic process: A preliminary study. Journal of Constructivist Psychology, 30(4), 371-387.

Russell, S. M., Funke, G. J., Knott, B. A., \& Strang, A. J. (2012, September). Recurrence quantification analysis used to assess team communication in simulated air battle management. In Proceedings of the Human Factors and Ergonomics Society Annual Meeting (Vol. 56, No. 1, pp. 468-472). Los Angeles, CA: Sage.

Schiepek, G., Eckert, H., Aas, B., Wallot, S., \& Wallot, A. (2015). Integrative psychotherapy: A feedback-driven dynamic systems approach. Göttingen: Hogrefe Publishing.

Schiepek, G., Fricke, B., \& Kaimer, P. (1992). Synergetics of psychotherapy. In W. Tschacher, G. Schiepek, \& E. J. Brunner (Eds.), Self-organization and clinical psychology (pp. 239-267). Berlin: Springer.

Schmidt, R., Morr, S., Fitzpatrick, P., \& Richardson, M. J. (2012). Measuring the dynamics of interactional synchrony. Journal of Nonverbal Behavior, 36(4), 263-279.

*Schoenherr, D., Paulick, J., Strauss, B. M., Deisenhofer, A. K., Schwartz, B., Rubel, J. A., ..., Altmann, U. (2019). Nonverbal synchrony predicts premature termination of psychotherapy for social anxiety disorder. Psychotherapy. https://doi.org/10.1037/ pst0000216.

Seligman, M. E. (1995). The effectiveness of psychotherapy: The consumer reports study. American Psychologist, 50(12), 965-974.

Singer, T., \& Lamm, C. (2009). The social neuroscience of empathy. Annals of the New York Academy of Sciences, 1156(1), 81-96.

Singer, T., \& Engert, V. (2019). It matters what you practice: Differential training effects on subjective experience, behavior, brain and body in the ReSource Project. Current Opinion in Psychology, $28,151-158$.

Steele, J. S., Ferrer, E., \& Nesselroade, J. R. (2014). An idiographic approach to estimating models of dyadic interactions with differential equations. Psychometrika, 79(4), 675-700.

Steffensen, S., \& Pedersen, S. B. (2014). Temporal dynamics in human interaction. Cybernetics \& Human Knowing, 21(1-2), 80-97.

*Stratford, T., Lal, S., \& Meara, A. (2009). Neurophysiology of therapeutic alliance. Gestalt Journal of Australia and New Zealand, $5(2), 19-47$.

*Stratford, T., Lal, S., \& Meara, A. (2012). Neuroanalysis of therapeutic alliance in the symptomatically anxious: The physiological connection revealed between therapist and client. American Journal of Psychotherapy, 66(1), 1-21.

*Stratford, T., Meara, A., \& Lal, S. (2014). Heart rate variability and the anxious client: cardiac autonomic and behavioral associations with therapeutic alliance. The Journal of Nervous and Mental Disease, 202(8), 613-619.

Strogatz, S. H., \& Stewart, I. (1993). Coupled oscillators and biological synchronization. Scientific American, 269(6), 102-109.

*Thomas, K. M., Hopwood, C. J., Woody, E., Ethier, N., \& Sadler, P. (2014). Momentary assessment of interpersonal process in psychotherapy. Journal of Counseling Psychology, 61(1), 1-14.

Tilsen, S. (2009). Multitimescale dynamical interactions between speech rhythm and gesture. Cognitive Science, 33(5), 839-879.

Timmons, A. C., Margolin, G., \& Saxbe, D. E. (2015). Physiological linkage in couples and its implications for individual and 
interpersonal functioning: A literature review. Journal of Family Psychology, 29(5), 720-731.

*Tomicic, A., Pérez, J. C., Martínez, C., \& Rodríguez, E. (2016). Vocalization-silence dynamic patterns: A system for measuring coordination in psychotherapeutic dyadic conversations. Revista Latinoamericana de Psicología, 49(1), 48-60.

*Tracey, T. J., Sherry, P., \& Albright, J. M. (1999). The interpersonal process of cognitive-behavioral therapy: An examination of complementarity over the course of treatment. Journal of Counseling Psychology, 46(1), 80-91.

*Tschacher, W., \& Meier, D. (2019). Physiological synchrony in psychotherapy sessions. Psychotherapy Research. https://doi. org/10.1080/10503307.2019.1612114.

Turvey, M. T. (1990). Coordination. American Psychologist, 45(8), 938-953.

Wampold, B. E., \& Imel, Z. E. (2015). The great psychotherapy debate: The evidence for what makes psychotherapy work. New York: Routledge.

Wiggins, J. S. (1996). An informal history of the interpersonal circumplex tradition. Journal of Personality Assessment, 66(2), 217-233.

Wiltermuth, S. S., \& Heath, C. (2009). Synchrony and cooperation. Psychological Science, 20(1), 1-5.
Wiltshire, T. J., Butner, J. E., \& Fiore, S. M. (2018). Problem-solving phase transitions during team collaboration. Cognitive Science, 42(1), 129-167.

Wiltshire, T. J., \& Fiore, S. M. (2014). Social cognitive and affective neuroscience in human-machine systems: A roadmap for improving training, human-robot interaction, and team performance. IEEE Transactions on Human-Machine Systems, 44(6), 779-787.

Wiltshire, T. J., Steffensen, S. V., \& Likens, A. D. (2020). Challenges for using coordination-based measures to augment collaborative social interactions. In K. Viol, H. Schöller, \& W. Aichhorn (Eds.), Selbstorganisation - ein Paradigma für die Humanwissenschaften (pp. 201-216). Wiesbaden: Springer. https://doi. org/10.1007/978-3-658-29906-4_13.

Publisher's Note Springer Nature remains neutral with regard to jurisdictional claims in published maps and institutional affiliations. 